\title{
Otro escenario para el análisis de la recepción: la canción de amor huichola y la música Banda ${ }^{1}$
}

\author{
Sarah Corona Berkin ${ }^{2}$
}

\begin{abstract}
El ocaso de nuestra imagen del amor sería una catástrofe mayor que el derrumbe de nuestros sistemas económicos y políticos: sería el fin de nuestra civilización. O sea: de nuestra forma de sentir y vivir.
\end{abstract}

Octavio Paz

La EXISTENCIA DE UNA INMENSA LITERATURA sobre el amor (Corona Rodríguez, 2000), el éxito que disfrutan los medios masivos de comunicación cuya temática principal es el amor, la antigüedad con que aparece el amor en Oriente y Occidente, nos hacen pensar en la universalidad del sentimiento y nos generan preguntas sobre distintas prácticas y saberes amorosos.

Las diferencias entre el amor occidental actual, en un contexto tecnológico y permeado por los medios masivos de comunicación y el amor huichol, en un contexto étnico alejado de la modernidad, es mi interés. Considero que partir del amor como objeto de estudio, permite aproximarse a las formas de sentir y pensar de una sociedad, de las fuentes que construyen su cultura y de la ética que persiguen. Hay poco escrito sobre la situación actual del amor y menos existe sobre las prácticas diversas, como las de los huicholes, sus códigos amorosos y sus transformaciones y las formas en que están ligadas al poder.

Para abordar los diferentes conceptos de amor, he recopilado 100 cartas de amor de jóvenes huicholes y otro tanto de jóvenes mestizos de la ciudad de Guadalajara. También he recurrido a un trabajo etnológico y a bibliografía sobre el matrimonio y las relaciones entre los sexos y he recopilado y traducido canciones

1. Esta investigación se ha financiado parcialmente por el convenio conACYT n. 28607-s.

2. Universidad de Guadalajara. 
dé amor tradicionales, contemporáneas huicholes y de Banda norteña que se escucha en la Sierra Huichol. Con el objeto de acercarme a la radio, como una de las "instituciones educativas" del amor en ambos grupos de jóvenes, en este lugar hablaré únicamente de las canciones, ya que a diferencia de las cartas, donde sus referentes son más amplios y antiguos, las canciones pueden considerarse discursos directamente relacionados con los medios masivos de comunicación y la producción cultural actual.

\section{Punto de partida}

Sabemos hoy con certeza que los medios electrónicos proponen formas de comunicación que son apropiadas por los receptores según su edad, género y entorno sociocultural. Sin embargo, decir que los contextos determinan la apropiación o recepción que hagan los sujetos de los medios electrónicos, es señalar finalmente como punto de convergencia a los medios masivos de comunicación. De allí que propongo partir de las producciones comunicativas de los distintos sujetos productores de discursos, como otra perspectiva de análisis para acercarnos a los sujetos, que, entre otras cosas, "reciben mensajes" de los medios masivos de comunicación. Conocer las canciones de amor producidas por huicholes nos acerca a la relación de los mensajes mediáticos en contextos de culturas orales, permeados parcialmente por la escritura y la imagen. Además nos permite acercarnos al amor en una comunidad ajena a otros medios masivos de comunicación, entre otras variables, y al posible impacto de la música comercial en las prácticas amorosas occidentales (Attali, 1995).

\section{Prejuicios teóricos}

Con "prejuicios teóricos" aludo a los antecedentes teóricos que marcan la construcción de esta investigación. Un estudio de esta problemática creemos que debe abarcar por lo menos tres ópticas teóricas:

1. Partir de la etnografía comunicativa, es decir del entorno sociocultural que rodea a los sujetos y que marca los límites físicos y sociales a sus competencias comunicativas. Asimismo, el prestigio que se les otorga, el contenido, el motivo y las formas en que los diferentes sujetos ejercen, ya sea la escritura, la oralidad o la imagen, marcará las fronteras de dichas prácticas comunicativas (Heath, 1983). 
2. Abordar el problema de la construcción del sujeto y su relación con los medios masivos de comunicación y sus discursos (Barthes, 1982). El poder considerado como red que atraviesa los cuerpos y los disciplina, debe ser punto de reflexión en un trabajo donde las distintas culturas se aproximan (Foucault, 1976).

3. Las tecnologías comunicativas tienen a su vez ciertas especificidades que marcan los usos que se les puedan atribuir. A Marshal McLuhan (1969) se le debe la frase "el medio es el mensaje", pero desde sus pioneras reflexiones poco se ha avanzado en el estudio sobre la especificidad de los medios de comunicación. Creemos que los trabajos de McLuhan, criticados por su descontextualización histórica y política y sus conclusiones apresuradas, deben ser retomadas a la luz de disciplinas como la psicología, la etnología y la comunicación social para entender las especificidades de los medios de comunicación en los contextos que marcan las diferentes prácticas comunicativas.

\section{La canción y el amor en una comunidad huichol}

La investigación se llevó a cabo con los alumnos y maestros de la escuela secundaria Tatusi Maxakwaxi o "Nuestro Abuelo Cola de Venado", en San Miguel Huaixtita. Esta comunidad se encuentra en la parte norte del Estado de Jalisco en la Sierra Madre Occidental, poblada por 710 indios huicholes. Los huicholes son uno de los 54 grupos indígenas de México con mayor porcentaje de monolingüísmo, es decir, que únicamente hablan su lengua. Mientras 91 por ciento de los indígenas nacionales son cristianos, en el caso de los huicholes sólo 48 por ciento declaró serlo. En San Miguel Huaixtita los huicholes no practican rituales cristianos y la comunidad se organiza alrededor de autoridades tradicionales y prácticas rituales propias. Aunado a estas características, lo inaccesible de su territorio, la ausencia de carreteras, electricidad, medios masivos de comunicación, pueden ayudar a explicar la permanencia de sus costumbres y tradiciones así como la importancia que le otorgan a la conservación de su identidad étnica. La radio es el único medio masivo de comunicación al que tienen acceso diariamente a través de aparatos de pilas, aunque la recepción clara de las radiodifusoras de Nayarit, San Luis Potosí y el Distrito Federal, es posible únicamente de noche o temprano por la mañana. Algunos jóvenes huicholes tienen "walkmans" que les permites además oir cassettes de música grabados, ya sea de grupos de banda norteños comprados en la ciudad, de grupos huicholes grabados por pequeñas compañías de grabación o cassettes grabados por 
ellos mismos de la radio y durante eventos en su comunidad. La cánción tradicional se acompaña de instrumentos musicales que se fabrican en la Sierra: una pequeña guitarra de 5 cuerdas y una pequeño violín de cuatro cuerdas. Estos instrumentos son fabricados por los hombres, ya que se cree que las mujeres que realizan esta tarea tendrán hijos "muy chillones". La canción moderna huichola se acompaña de instrumentos como la guitarra mexicana que la acercan más al ritmo mestizo de bandas.

En relación a sus prácticas amorosas, sabemos que los huicholes más tradicionales casan a sus hijos e hijas en un arreglo temprano. No existe en el idioma huichol una palabra para "novio" en el sentido occidental. Existen "nek'na" o esposo, o bien "tuxeri", "cuando ya está hecho" pero no están casados. Esta última palabra, explica Benita, suena feo y no se dice delante de los niños. Los hombres y las mujeres tienen prohibido hablarse, salvo lo indispensable, por lo cual, si un hombre y una mujer están conversando, pronto se rumorará que es su "tuxeri". No hay una palabra equivalente a "amor". Te quiero, lo quiero, te necesito, te extraño, tengo celos de ti, son expresiones completas del sentimiento, pero una "palabra chica" para amor, subraya Benita, no hay. En huichol "te quiero" se dice con una sola palabra: nematseuyewua.

Las relaciones sexuales no legítimas están fuertemente penadas después de la muerte. Agustín, en sus "Apuntes para la cultura wixarika", dice a sus alumnos: "Hoy que tenemos nuestro cuerpo hay que cuidarlo, porque uno no vive para siempre, algún día nos iremos, así cuenta la tradición. Dicen que cuando vas al infierno, el castigo es duro, que recibes la comida sucia, podrida y agusanada. El castigo es más fuerte si tienes amantes animales o amantes que no son de la misma raza." "¿Cuál pecado más se prohibe?" continúa en otra clase el maestro Agustín: "Cuando tiene muchos amoríos. Si tiene diez, ya es mucho pecado. La tradición dice que allá no se castiga cuando es de ninguno a cinco. Si tiene muchos, lo van a cargar con penes en su morral, se va a llenar su morral y se van a convertir en piedra, muy pesados. Si es hombre, lo van a cargar con vaginas". Los huicholes son polígamos pero no es regular que tengan más de una esposa. Se supone que la pareja debe ser fiel, sin embargo la realidad es otra: "la infidelidad es frecuente entre los hombres como entre las mujeres. De ordinario esto no tiene consecuencias graves y se observa con impasibilidad por parte de la mayoría de miembros de la comunidad." (Fuster y Nahmad, 1972:44-45). Durante los viajes ceremoniales a Wirikuta, en San Luis Potosí, todos los peregrinos deben confesar públicamente sus infidelidades, por las que el marakame amarra un nudo en una larga cuerda por cada una de ellas. Al final, la cuerda es lanzada al fuego, a Tatewarí, quien purifica y termina con ese pasado. El divorcio no es muy dificil y los hombres y las mujeres pueden iniciar otros 
matrimonios y familias. El concepto de hijos legítimos e ilegítimos no existe y los esposos y esposas de sus padres son también su "papá" o "mamá".

Por otro lado, el amor, como sentimiento, aparece en todos los pueblos y en todos ellos existen narraciones sobre el encuentro de dos personas y su atracción mutua y el origen de su civilización. En la mitología huichol, el primer encuentro amoroso, de donde nace el pueblo huichol, es entre Huetácame y la mujer-perro. La historia, en donde algunos han reconocido similitudes con el arca de Noé, cuenta que Huetácame, un huichol muy trabajador, fue sorprendido por Nacawé, la madre de los dioses, al ver que su esfuerzo de limpiar su tierra para sembrar no prosperaba. Mientras más limpiaba, más árboles y breña crecía. Al quinto día, inesperadamente Nakawé le dijo que no debía más limpiar la tierra sino cortar un árbol de "chalate" y hacer con el tronco una canoa donde debía meter semillas de todas las especies. Además llevaría especies de aves y animales y a su perrita negra. Pasado el gran diluvio, Huetácame bajó a tierra y empezó la nueva vida en las cinco direcciones del mundo, instaló su hogar "en el lugar del centro, del medio". Alli siembra y realiza las labores cotidianas del huichol. La perrita negra creció y esperaba a diario a Huetákame en su casa, y siempre que éste regresaba, encontraba tortillas calientes para comer. En su extrañeza, un día encuentra la piel de la perrita y la hecha al fuego. Cuando la piel se quema, se escucharon fuertes alaridos de dolor de su perrita, la cual encontró, llorando, transformada en una mujer desnuda. Huetácame la baña con agua y con masa de maíz y le dice "tu fuiste mi perrita, pero ahora serás mi mujer, vas a hacer la comida, a tortear y estar conmigo" (De la Torre, 1999:6). Huetákame y su mujer tuvieron muchos hijos con los que poblaron la tierra.

En cuanto a la música que se produce y escucha en San Miguel Huaixtita, podemos distinguir por lo menos cuatro tipos: música sagrada, música profana antigua (tradicional), música contemporánea huichol cantada en español y en huichol, finalmente la música ranchera y de banda mestiza que se recibe de las estaciones de radio que se escuchan.

Los huicholes conocen diversos instrumentos de música, algunos muy arcaicos como el "tepo" o tambor hecho del tronco de un árbol ritualmente elegido. Existen también diversas sonajas hechas de calabaza que se usan en la fiesta Tatei Neira para anunciar la llegada de los "pequeños peyoteros" de su expedición simbólica a Wirikuta. La guitarra de cinco cuerdas o "canari" y el violín de cuatro cuerdas o "shahuerí" acompaña la canción sagrada así como las demás. En el caso de la música contemporánea huichol, se han agregado el vigüela, el bajo y la guitarra mexicana.

Los marakames cantan los mitos sagrados durante las ceremonias comunales, en los viajes a Wirikuta, así como en eventos familiares como entierros donde se 
busca información sobre el alma del difunto, ya que la canción sagrada comunica al marakame con los dioses. El marakame toca el tepo con las palmas de las manos mientras canta, produciendo un monótono sonido que se escucha a gran distancia en el silencio de las montañas.

La música tradicional antigua es ejecutada en los pequeños violines y guitarras, hechos por los propios músicos. Zinng (1982) cuenta que los huicholes tocan esta música para su propio entretenimiento y no para compartir con la comunidad. Las composiciones son individuales y cantadas en soledad o pequeños grupos.

Existe otra música que se toca en compañía y durante las fiestas y borracheras después de las ceremonias. Estas canciones pueden ser en huichol y originalmente eran traducciones de canciones mestizas. Canciones como "Guadalajara en un llano, México en una laguna", eran cantadas en huichol en la "Voz de los cuatro pueblos". Ya para 1994 se habían grabado varios cassettes de este tipo de música. Después de esta primera época, los grupos huicholes que cantaban música mestiza en las fiestas en la Sierra, empezaron a componer sus propias canciones, aunque la música continuó siendo "ranchera". Zinng dice: "Los huicholes gustan de la vivaz y variada música popular mexicana más que de la propia. Es uno de los pocos mexicanismos apreciados por los huicholes" (1982:27). Hoy son conocidos los grupos huicholes: Teupa, Enero 97 (antes Grupo Gachupines) y Venado Azul. La secundaria Tatutsi Maxakwaxi grabó en diciembre de 1999 su primer cassette.

\section{Metodología}

Se eligieron 45 canciones: 15 de amor tradicional huichol, 15 de amor de banda mestiza y 15 de amor contemporánea huichola. Estas canciones fueron recopiladas y grabadas con la ayuda de César Chávez Martínez, joven huichol, informante para esta investigación. Se reunieron canciones tradicionales y contemporáneas de la comunidad huichola y de los grupos huicholes "Enero 97" y "Teupas", traduciéndolas al español. El resto de las canciones tradicionales fueron extraídas del libro $\mathrm{La}$ canción Huichola (Ramírez de la Cruz, 1993), y las quince canciones de banda mestiza se compilaron de la radio, de los grupos e interpretes conocidos en las comunidades huicholes.

Se manifestaron las preferencias musicales en una encuesta que se aplicó entre los jóvenes de San Miguel Huaxtita, obteniendo información en cuanto al grupo musical favorito, estaciones preferidas, tiempo dedicado a escuchar la radio, los noticieros y radionovelas (cuadros $1,2,3$ y 4 ). 
CUADRO 1

Estaciones que escucha

\begin{tabular}{|c|c|}
\hline HoMbres & MuJeres \\
\hline XEJMN La voz de los 4 pueblos & XEJMN La voz de los 4 pueblos \\
\hline La Triunfadora & La Triunfadora \\
\hline La Ranchera de Monterrey & WA San Luis P. \\
\hline W de México D.F. & W de México D.F. \\
\hline Ke-Buena & Ke-Buena \\
\hline WUA & Ixtlan \\
\hline Radio Educación & Super Ranchera \\
\hline El Gallo & \\
\hline
\end{tabular}

Encuesta aplicada a 100 jóvenes huicholes de la escuela secundaria Tatutsi Maxakwaxi en 1998.

CUADRO 2

Estación favorita

\begin{tabular}{|c|c|}
\hline Hombres & MuJeres \\
\hline XEJMN La voz de los 4 pueblos & La Triunfadora \\
\hline La Triunfadora & XEJMN La voz de los 4 pueblos \\
\hline WA San Luis P. & WA San Luis P. \\
\hline & La Ranchera de Monterrey \\
\hline
\end{tabular}


CUADRO 3

Grupo musical favorito

\begin{tabular}{|l|l|}
\hline \multicolumn{1}{|c|}{ Hombres } & \multicolumn{1}{c|}{ MuJeres } \\
\hline Los Tucanes & Música Tradicional \\
\hline Banda Limón & Banda del Recodo \\
\hline Música Tradicional & Banda Machos \\
\hline Los Temerarios & Los Tucanes \\
\hline Banda del Recodo & Banda Cuisillos \\
\hline Banda Maguey & Los Únicos de México \\
\hline Banda Limite & Banda Maguey \\
\hline Marco Antonio Solís & Música Ranchera \\
\hline Country & Los Gachupines \\
\hline Norteño & Los Temerarios \\
\hline Los Únicos de México & Grupo Mojado \\
\hline Grupo Tentación & Grupo Heredero \\
\hline Los Coralillos & Tigres del Norte \\
\hline Banda Machos & Banda Sinaloense \\
\hline Banda Cuisillos & ElVenado Azul \\
\hline Huracanes del Norte & Chalino Sánchez \\
\hline Mandingo & Banda Limón \\
\hline Joan Sebastián & Bertín y Lalo \\
\hline Tigres del Norte & \\
\hline Grupo Mojado & \\
\hline Antonio Aguilar & \\
\hline
\end{tabular}

CUADRO 4

Tiempo dedicado a escuchar música

\begin{tabular}{|c|c|}
\hline HOMBRES & MuJeres \\
\hline $\begin{array}{l}\text { Entre } 6 \text { a.m. y } 11 \text { p.m. } \\
\text { Mayoría de } 2 \text { a } 3 \text { horas } \\
\text { Algunos hasta } 9 \text { horas } \\
\text { El domingo todo el día }\end{array}$ & $\begin{array}{l}\text { Entre } 6 \text { a.m. y } 10 \text { p.m. } \\
\text { Mayoría de } 1 \text { a } 2 \text { horas } \\
\text { Algunas hasta } 9 \text { horas } \\
\text { Todo el dia Sábado } \\
\text { y Domingo y en la noche }\end{array}$ \\
\hline
\end{tabular}


¿Escuchas noticieros?

\begin{tabular}{|c|c|}
\hline Hombres (25) & MuJeres (24) \\
\hline SI (80 por ciento) & SI (83 por ciento) \\
\hline NO (20 por ciento) & NO (17 por ciento) \\
\hline
\end{tabular}

¿Escuchas radionovelas?

\begin{tabular}{|c|c|}
\hline Mujeres (24) & Hombres (28) \\
\hline SI (58 por ciento) & SI (42 por ciento) \\
\hline NO (42 por ciento) & NO (58 por ciento) \\
\hline
\end{tabular}

De estos datos se observó la gran aceptación de los grupos de música de banda mestizos, la variedad y las preferencias. En lo correspondiente a los gustos y tiempos destinados a escuchar la radio, es similar en hombres y mujeres.

En el análisis del corpus de canciones se puede concluir que existen elementos recurrentes en las representaciones del amor. Hemos agrupado en cuatro estos elementos o figuras, como llama Barthes a estos "retazos" del discurso amoroso. Estos son: 1) "Te quiero, no te quiero"; 2) "Te llamas amor"; 3) "El tiempo del amor"; 4) "El y ella".

\section{Te quiero, no te quiero}

El tema de las canciones permite ver la relación entre los enamorados. Encontramos tres opciones: amor feliz, amor imposible y desamor (cuadro 5). Las canciones de creación occidental se distinguen por sumar un bajo 33 por ciento de amor feliz. Esta cifra es apenas superior al 20 por ciento de canciones de amor feliz que encuentra De la Peza (1996) en un corpus de 635 boleros. Lograda la satisfacción 
erótica, el deseo alcanzado, realizada la "completud", el amante se siente traicionado, abandonado, solo: "naufrago la pasión que terminaba", "por quererla tanto, tanto, a donde vine a parar", "yo te quise, yo te amaba, y ahora sólo sé te aborrecer".

Pareciera que el enamorado se aleja de la intensidad del sentimiento, tomando distancia, abandonando o sintiéndose abandonado. La pasión amorosa es deseada pero es imposible tener continuidad. Como exclama Barthes, nuestra cultura actual

\section{CUADRO 5}

1) AMOR Feliz. Sentimiento actual, unido, sin conflictos. 2) AMOR IMPOSIBLE. Abandono, error, problemas irresolubles, amor perdido, mal correspondido. 3) Desamor. Ya no te quiero.

Canción Banda

\begin{tabular}{|c|c|c|}
\hline Tema & Canciones & Porcentaje \\
\hline 1 & 5 & 33 por ciento \\
\hline 2 & 8 & 53 por ciento \\
\hline 3 & 2 & 13 por ciento \\
\hline
\end{tabular}

Canción Tradicional

\begin{tabular}{|c|c|c|}
\hline Tema & Canciones & Porcentaje \\
\hline 1 & 12 & 79 por ciento \\
\hline 2 & 3 & 20 por ciento \\
\hline 3 & 0 & 0 por ciento \\
\hline
\end{tabular}

Canción Contemporánea

\begin{tabular}{|l|c|c|}
\hline Tema & Canciones & Porcentaje \\
\hline 1 & 11 & 73 por ciento \\
\hline 2 & 3 & 20 por ciento \\
\hline 3 & 0 & 0 por ciento \\
\hline otras & 1 & 6 por ciento \\
\hline
\end{tabular}


es "frígida", o más ampliamente Octavio Paz: "Nuestro tiempo es simplista, sumario y brutal. Después de haber creído en la idolatría de los sistemas ideológicos, nuestro siglo ha terminado en la adoración de las Cosas. ¿Qué lugar tiene el amor en un mundo como el nuestro?" (Paz, 1993:151).

En contraste, con 79 por ciento de amor feliz, la canción huichol parece tener otro objetivo. En el origen de lo amoroso huichol está la naturaleza. Frente al concepto moderno, desvinculado de la naturaleza y de lo sobrenatural, está un hombre que se comunica con los dioses, con las montañas, el aire, las plantas y los animales. El amor trasluce la naturaleza y los enamorados se reconocen en ella: "hasta mi burro está triste", "viviendo yo solito me moriré, como un arbolito voy a ser", "Eres la flor, la flor nomás". El amor imposible se canta en menor proporción, pero el dasamor no pareciera existir. El huichol pone énfasis en la vida y por lo tanto en la unidad esencial masculino-femenino que es la condición de la vida misma, de la sobrevivencia social, fisica y sobrenatural que en su cultura son lo mismo.

\section{Te llamas amor}

La utilización de las personas gramaticales es similar en los tres tipos de canciones: una primera persona que se dirige a una segunda del singular (cuadro 6). Esto se explicará ya que, como dice Barthes, "amar" en infinitivo, no existe. Siempre se ama a un "tú", y es un "tú" el objeto del sentimiento al que cantan todas las canciones de amor. Situados en la canción de amor, en el plan afectivo, y no el racional de la

CUADRO 6

Personas

\begin{tabular}{|l|c|c|c|}
\hline & Primera & Segunda & Tercera \\
\hline Banda & 2 & 13 & 0 \\
\hline Tradicional & 1 & 12 & 2 \\
\hline Contemporánea & 0 & 11 & 4 \\
\hline
\end{tabular}


descripción, hablar de amor, o cantarlo en este caso, requiere de apostrofarlo, es decir, hacer énfasis interpelando directamente al ser amado. En la canción huichol, a diferencia de la de Banda esta práctica se subraya aún más con el nombre propio: "Hija de Guillermo, yo estoy esperándote", "Hija de Tsaiwinu, tu eres mi corazón". En las canciones de Banda, prácticamente no se mencionan los nombres (cuadro 7).

CUADRO 7

NOMBrES

\begin{tabular}{|l|c|c|c|}
\hline & Banda & Tradicional & Contemporánea \\
\hline Mujeres & 2 & 13 & 0 \\
\hline Hombres & 1 & 12 & 2 \\
\hline
\end{tabular}

Además de observar una disminución en menciones de nombres propios, encontramos que en el caso de las canciones tradicionales, los nombres que se mencionan van acompañados del nombre de su padre: Silvia, hija de Martín, Sofía, hija de Isidro, Aurelia, hija de Guillermo, o en algunos casos se omite el nombre de la mujer y se identifica con el del padre: "Hija de Tereso". En los casos de canciones contemporáneas huicholes, desaparece la referencia al padre, pero los nombres propios, casi en su totalidad, son en lengua huichol: Iwiwiema, Kapaima, Xitaima, Haliema. Este cambio parece fortalecer las costumbres antiguas, antes del bautizo cristiano, de nombrar a los niños a partir de los sueños de los ancianos. De esta manera, en la actualidad, los nombres se conciben de nuevo especialmente para el niño o niña y se repiten poco y no tienen gran necesidad de apellido para identificarse: Flor de maíz nacido, El que mira, El que va crecer, Cuando las flores se hacen semillas, Cuando las nubes andan bajo, Cuando todo está floreando, son ejemplo de nombres propios huicholes. Los nombres de los hombres siguen el mismo patrón: Santos Ramírez, Lino y Heriberto en la canción tradicional, Miiweme en la contemporánea. Pareciera ser que el "tú" abstracto, comodín de cualquier consumidor de amor en la canción Banda, no ha tenido gran impacto en la canción huichol contemporánea, que al ritmo mestizo canta a los amores que tienen su nombre propio. 


\section{El tiempo del amor}

"Yo te quise, yo te amaba", "tan sólo me queda recordarte, como mi único amor", "Enamorarme para mi fue una hermosura, ahora resulta que ese fue mi peor error". Las canciones de Banda aluden a los recuerdos de un gran amor pasado (cuadro 8). El uso reiterado del pasado tiene un tono nostálgico al mirar hacia atrás los momentos felices del amor y añorar un estado perfecto con el ser amado. "La nostalgia implica una valoración positiva del pasado que se contrasta con el presente evaluado negativamente", afirma Davis (cit. De la Peza 1996), y de esta manera la canción de Banda parece mitificar el pasado y lo opone a un presente fracasado, triste o cuando menos incierto y amenazante. La nostalgia emerge en circunstancias culturales en las cuales se ve a la sociedad en transición permanente. La nostalgia así percibida es un fenómeno de la modernidad, es una respuesta afectiva a los drásticos, constantes y rápidos cambios de la época moderna. Carmen de la Peza (1996) observa este fenómeno social en el reciente retorno al bolero en los medios masivos de comunicación y el gusto del público. Pareciera que ante un futuro incierto, es mejor llorar por ese "pasado que siempre fue mejor."

\section{CUADRO 8}

TiEMPOS

\begin{tabular}{|l|c|c|c|}
\hline & Banda & Tradicional & ContemporáneA \\
\hline Pasado & 10 & 5 & $1+1$ \\
\hline Presente & 5 & 14 & 9 \\
\hline Futuro & 0 & $1+4$ & $5+3$ \\
\hline
\end{tabular}

La canción huichol tradicional y la contemporánea no registran esta necesidad. En sólo cinco de las canciones tradicionales y en una de las contemporáneas se recurre al pasado y no de forma nostálgica, sino para contextualizar el presente: "Escribiste sobre piedra, con las plumas del pino", "Estando yo aquí, trabajé, trabajé, creí en el trabajo y de nada, de nada, no me pagaron", "Despreciaste, despreciaste, linda amorcita, linda amorcita, y ya a tus ganados, no los apreciaste", "De otro pueblo, de otro pueblo, te vieron a ti, te vieron a ti, en San Miguel, en San Miguel... fuiste la reina, fuiste la reina", "A la Wirocha nos vamos, tu dijiste, tu dijiste". El 
pasado sirve para explicar lo que sucede en el presente; amores felices o infelices que tienen su origen en acciones pasadas: llegar de otro lado, prometer amor, despreciar lo que se tenía. Los huicholes no tienen nostalgia de un pasado que se encuentra vivo en el presente. Los cambios de su entorno son lentos, no se ha ahuyentado al pasado, cada día los "personajes" o dioses acompañan el diario fluir del presente. Jorge, presidente de la sociedad de padres de familia de Tatutsi Maxakwaxi, me aclara durante una ceremonia ritual: "los del gobierno vienen y nos dicen que tenemos que escribir nuestra tradición, nuestra costumbre, porque vamos a desaparecer. Pero eso es mentira, los niños están aquí y aprenden todo como debe ser." Para Jorge no hay lugar para la nostalgia de un pasado frente a un futuro incierto, nostalgia que invade a los funcionarios del INI, antropólogos y folkloristas, y de forma comercial, sentimiento de nostalgia que retrata la canción de Banda norteña. Para sobrevivir, el huichol no llora al pasado, sino se instala en el presente, lo acepta, lo disfruta y mira optimista hacia un futuro acorde con el pasado y el presente.

\section{El y ella}

El análisis mostró que la descripción que distintas canciones hacen del hombre y la mujer permiten caracterizar la naturaleza de la relación amorosa en cada caso.

En las canciones de Banda, similar a lo que sucede con los boleros (De la Peza, 1996) y en la canción ranchera (Corona, 1976), el hombre adopta la posición activa y como sujeto de la enunciación, reclama, declara su amor, insulta. Sus cualidades son el beber alcohol, el recordar o el olvidar (según sea el caso o la necesidad), oír música. La mujer sin voz en la canción de Banda, como cualidades posee ser "una ilusión" y su enamorado añora sus caricias, besos, sonidos, miradas, sentidos. Ser amiga, madre, novia, esposa en distintos momentos. En ninguna canción oímos la voz de ella.

En la canción huichol, las características de ella son específicas de cada mujer y son más concretas que la "ilusión" apreciada en las Bandas. La mujer huichol muestra una patente actividad: escribir, hablar inglés, trabajar, ser sincera, ayudar. En varias canciones se oye la voz femenina que adopta roles amorosos más activos que los mismos hombres de la canción de Banda: "Yo me llamo Kipaima, y ya estoy grandecita, usted todavía eres chico, te voy a robar y dí que si". Y continúa: "Yo seré tu mamá, usted mi chiquito, y ya después regresaremos, cuando ya estés grandecito". O bien los reclamos también pueden ser femeninos: " $¡$ Oye Heriberto! ¿Lo dijiste de corazón? ¿Por qué ahora no me quieres mirar?”. Las características del hombre son 
también más pragmáticas y podrian traducirse en el dicho popular "amor son hechos y no grandes acciones". Dar regalos, llevar a pasear a distintos lugares, comprar cosas, dar flores y hasta dinero, que a diferencia de la Banda, donde aparece el dinero relacionado a la "venta" de una mujer, en el huichol, el dinero es un regalo más.

En la mujer huichol, la ropa, los adornos, sus ojos, ser morena, son cualidades apreciadas. También el ser alegre y bailadora. Características negativas: ser loca, es decir, no recordar el pasado, ser chiquita y engañar. En los hombres, el aspecto negativo es regañar y no cumplir.

Ambas canciones huicholes, la contemporánea y la tradicional, coinciden en la visión activa de la mujer y la posición seductora del hombre. Frente al modelo de la canción de Banda, de conquista y resistencia, la pareja huichol busca la unión, mujerhombre, con la familia y con su entorno: "Allá en el mar, nos moriremos en nosotros".

Los resultados del análisis de las prácticas musicales revela:

1. Las transformaciones que sufre la canción huichol al contacto, entre otros, con la música de Banda. Hemos mostrado la trayectoria de la canción tradicional hacia la contemporánea para descubrir los códigos de lo amoroso que se difunden en la canción como parte de la cultura actual diversa.

2. El código de lo amoroso en los tres tipos de canciones presentan un modelo histórico-étnico de los comportamientos posibles en las relaciones de amor.

3. La idea del amor, como la conocemos actualmente, está en crisis porque el elemento indispensable para que exista, la persona, está perdiendo centralidad. El amor, que es a una persona única, a su cuerpo y alma, requiere de que el objeto de su deseo sea un sujeto. Hoy la amenaza de la destrucción de la persona viene no de los enemigos "antiguos, la iglesia y la moral de la abstinencia. Sino de la promiscuidad, que lo transforma en pasatiempo y el dinero, que lo convierte en servidumbre" (Paz,1993:171)

4. Conocer la producción discursiva y las competencias comunicativas de sujetos pertenecientes a diferentes entornos culturales, permite acercarnos a otros aspectos que configuran al receptor. Estamos conscientes del trabajo que queda por recorrer.

\section{Bibliografía}

Attali, Jacques, Ruidos. Ensayo sobre la economía politica de la música, Siglo XXI, México, 1995.

Barthes, Roland, Fragmentos de un discurso amoroso, México, Siglo xxI, 1982. 
Corona, Sarah y Rodríguez Zeyda, "El amor como vínculo social, discurso e historia: aproximaciones bibliográficas", en Espiral. Estudios sobre Estado y sociedad, Universidad de Guadalajara, enero/abril, 2000.

Corona Sarah, La canción popular mexicana. Ensayo de análisis actancial, Universidad Católica de Lovaina, Bélgica, 1976.

De la Peza, Carmen, "El sacrificio del amor es el olvido. Una aproximación al estudio del amor desdichado desde la perspectiva del bolero", en Tramas, n. 9, Universidad Autónoma Metropolitana-Xochimilco, junio, 1996.

Foucault, Michel, Vigilary Castigar, Siglo xxI, México,1976.

Furst Peter y Nahmad Salomón, Mitos y arte huichol, Sepsetenta, México, 1972. Heath, Shirley Brice, Ways with words. Language, life and work in communities and classrooms, Cambridge, 1983.

López de la Torre, Rafael, Wiraritari Wa Yeiyari, Universidad de Guadalajara, México, 1999.

McLuhan, Marshal, La comprensión de los medios como extensiones del hombre, Diana, México, 1969.

Paz, Octavio, La llama doble. Amor y erotismo, Seix Barral, México, 1993.

Salvador, Agustín, Apuntes para la cultura wixarika, Universidad de Guadalajara/ Tatutsi Maxakwari, México, 2000.

Zinng, Robert, Los huicholes. Una tribu de artistas, INI, México, 1982. 